\section{Mechanical Engineers in the Army}

ONE of the recommendations of the Beveridge Committee on Skilled Men in the Services was for the formation of a Corps of Mechanical Engineers in the Army (see Nature, March 7, p. 255). Replying to a question in the House of Commons on March 11, Mr. Duncan Sandys, Financial Secretary to the War Office, referred to this proposal to pool the mechanical engineering resources of the various Corps. He said that it has now been decided to bring together the greater part of the Army's engineering maintenance services and to form them into a new and separate Corps. The new Corps will be made up of three principal components : first, the entire engineering side of the R.A.O.C.; second, all the maintenance personnel of the R.A.S.C., with the exception of formation workshop platoons and independent companies; and third, a large part of the mechanical maintenance personnel of the Royal Engineers. These far-reaching measures of reorganization would entail not only extensive administrative changes but also large-scale transfers of personnel.

\section{Nervous Shock in Peace and War}

At a Chadwick Public Lecture delivered on March 17, Dr. William A. Brend considered nervous shock in peace and war. 'Nervous shock' is the same whether it is called 'nervous shock', 'shell shock' or 'traumatic neurasthenia' or any other of its names. Evidence of nervous shock can be found in early records, for example, in the Book of Job. Shakespeare gives an astonishingly accurate picture of 'battleshock' in Henry IV. The modern history of the disorder begins about the middle of the nineteenth century when numerous cases were attributed to railway accidents. Many cases were seen in the Army during the War of 1914-18, and after the War a committee of investigation reported that the term 'shell-shock' had been 'a gross and costly misnomer"' which had done much harm. The essential cause of nervous shock is fear, but the effect of fear is often increased by injudicious 'suggestion'. Physical injuries play no part in the production of the disorder. Civilians suffering from shock after air-raids are not entitled to compensation under the Personal Injuries Act. Reasons were given for thinking that this was a very wise decision of Parliament. The influence of temperament was briefly discussed.

The biological significance of fear as an instinct was then examined. Capacity to feel fear is part of our normal mental make-up, and of the defence mechanism of the species. Fear only becomes a matter of self-reproach (that is, cowardice) if it is uncontrolled. Man then sinks to the level of the brutes and sacrifices the benefit of his intelligence. The public health aspect of nervous shock arises from the fact that the affection differs from organic disease or injury in that medical men are not con. sidered to have a monopoly of the knowledge concerning either the cause or the pathology or the proper treatment of the disorder. There is a definite public opinion on all these questions which expresses itself through the Press and influences Acts of Parliament, provision of treatment and claims for damages, etc., in courts of law acting through judges and juries. It is very important, therefore, that this public opinion should be based on accurate knowledge. There are reasons for thinking that this is not the case at present, and indeed that in certain directions encouragement is given to the develop. ment of the disorder. Increased understanding of the nature of the condition would accordingly help to reduce its incidence.

\section{Physical Society Optical Group}

THE inaugural meetings of the newly formed Optical Group of the Physical Society were held on March 6 at the Science Museum and the Imperial College, South Kensington. It is ten years ago since the Optical Society was merged with the Physical Society, and although in this period a good number of meetings have been devoted to optical subjects, there has been a widely expressed desire for the formation of a Group for discussions and lectures of a less exacting and critical character than those associated with papers intended as original contributions to science. A preliminary meeting was held in December 1941 at which a draft constitution was approved, the objects of the Group being the provision of opportunities for the meeting of those with optical interests, the promotion of research and education in optics (including the improvement of optical literature), and fostering public interest in this branch of science. The first business of the inaugural meeting was to adopt the Constitution, and to elect Dr. A. O. Rankine as chairman with Prof. L. C. Martin as honorary secretary. A representative committee consists of Instructor Capt. T. Y. Baker, Mr. R. J. Bracey, Mr. W. H. A. Fincham, Dr. V. G. W. Harrison, Mr. W. C. Hynd, Dr. H. Lowery, Capt. T. Martin. Mr. J. Perry and Mr. E. W. H. Selwyn.

The first lecture was delivered by Dr. W. M. Hampton (Messrs. Chance Bros. and Co., Ltd.) who took as his subject "Some Problems relating to Optical Glass", dealing especially with recent work on the effects of heat treatment on the optical properties of the medium. The meeting in the afternoon was devoted to a paper by Mr. R. J. Bracey describing "A Multi-purpose Collimator" and a discussion, opened by Mr. J. Perry, on "Thermal Effects on the Performance of Lens Systems". Both subjects provoked a good discussion in which valuable technical points were brought out. Upwards of fifty members attended a luncheon at which Profs. A. V. Hill and A. C. G. Egerton, secretaries of the Royal Society, were guests of the Physical Society. In proposing the toast "The Optical Group", Dr. Rankine said the membership already includes 127 names. $\mathrm{He}$ hopes that the formation of the Group will be of value in the scientific life of the country, and that where papers of optical interest are forthcoming they will in future be made available for discussion by its members. Exacting demands are being made upon the optical industry in Great Britain, and the new Group can do considerable service if it leads to increased co-operation among those whose duty and honour it is to be called upon to fulfil them.

\section{Royal Microscopical Society (1839-1939)}

THE recent publication of the presidential address delivered by J. E. Barnard before the Royal Microscopical Society (J. Roy. Mic. Soc., 61, $1 ; 1941$ ) in celebration of its centenary, and the republication in the same journal of the address given in 1895 by A. D. Michael (the president in that year) calls forcibly to mind the comparatively recent advent of the microscope particularly as applied to the variety of fields in which it is now so familiar. At the time 
of the foundation of this Society, microscopes were primitive and were generally regarded as playthings compared to the telescope, although Lister had already published his epoch-making paper on the achromatic objective. The paucity of microscopical research in Great Britain had, in fact, already been noted by Schleiden, a slur which the Society was to do much to remove. Under Prof. Owen as first president the Society flourished from the start, and the first number of the Journal was published in 1841. One of whe main features of the early meetings, attended in the nature of things almost exclusively by amateurs, was apparently the rapid introduction of new types of microscopes and much enthusiasm over technical improvements upon old. Among the members of the time we may note such names as John Queckett, Michael Faraday, Thomas Bell, with Ehrenberg as the first honorary fellow. Throughout its life the Society has stimula. ted interest not only in improvement of instruments but also in perfection of microscopical technique. The use of Canada balsam had been described shortly before the foundation of the Society, but it was not until 1848 that the use of glycerine was noted by Warrington.

In its first fifty years the Society achieved muchthe homogeneous immersion lens suggested by Stephenson and worked out by Abbe, the binocular microscope, the Society's standard screw for objectives, the mechanical substage and hundreds of other improvements large and small-and in its Journal were presented many epoch-making papers the authors of which are now almost forgotten but whose work has formed a sure foundation for modern studies. In more recent times the Society has become progressively professional. Among the outstanding features of these later years we may recall the controversy over Abbe's diffraction theory of microscopic vision, with E. M. Nelson and J. W. Gordon us the more notable figures and calling to mind such great names as Sylvanus Thompson and Lord Rayleigh, a topic which has arisen from time to time during ensuing years, culminating in 1928, when it was generally agreed that under the conditions of illumination commonly employed the theory is no longer tenable. In 1902 siedentopf introduced the ultra-microscope and in the following year the first paper appeared on ultra-violet light microscopy, marking perhaps the most important advance during the present century. The basis for the modern standard of procedure in microscopy was laid by Nelson in 1910 in a description of his method of "critical microscopy". Since that time, perhaps one of the more notable advances with which the Society has been connected is the improvement in design and the use of the polarizing microscope figuring so largely in current microscopy. It is confidently to be expected that in the future the Society will continue to serve microscopy with the same success as in the past. (See also Nature, 144, 850; 1939.)

\section{The Australian Anthropological Association}

In 1939 the Australian Anthropological Association was formed after discussion between the Anthropological Associations of New South Wales, Victoria and South Australia at the meeting of the Australian and New Zealand Association for the Advancement of Science held in Canberra that year. The headquarters of the new Association are to be situated in rotation for a period of two years in each State of the
Commonwealth in which there is an anthropological society affiliated with the Association. During the first two years of its existence the headquarters of the Association were in Adelaide. Now they are at Sydney and will remain there until October 1, 1943, when they will be transferred to Melbourne. The official organ of the Association is Mankind which is the official journal of the Anthropological Society of South Australia. Officers of the Association are as follows : President, Prof. A. P. Elkin ; Vice-president, Mr. F. L. S. Bell; Hon. Secretary-Treasurer, Mr. G. W. Watkins ("Hansard" Staff, Parliamentary House, Sydney).

\section{Early Civil Engineering in France}

IN a paper read to the Newcomen Society on March 11 entitled "The French Civil Engineers of the Eighteenth Century", Mr. S. B. Hamilton gave an account of the Corps des Ponts et Chaussées, founded in 1716, and of the school established in 1747 in connexion with it. The Corps was responsible for the main roads, canals, bridges, etc., of the country, and it has had many distinguished men on its staff. These men, such as Gautier, Frézier, Perronet, Gauthey, Chezy and Prony, possessed high scientific attainments, and in their memoirs and text books they established many of the principles underlying constructional work. When Telford looked for the literature of eivil engineering, it was to France he turned, and his collection of books was bequeathed to the Institution of Civil Engineers. The outstanding man of the eighteenth century was Perronet (1708-94), who entered the Corps in 1745 and became director of the École des Ponts et Chaussées in 1747. His bridges, said Mr. Hamilton, were remarkable for boldness of design. Moreover, in an age of corruption, he set his face against the patronage which ruined some civil administrations; he selected his subordinates strictly on the grounds of ability and character.

\section{Indian Journal of Genetics and Plant Breeding}

THE formation of the Indian Society of Genetics and Plant Breeding at New Delhi in January 1942 has been quickly followed by the publication of the Indian Journal of Genetics and Plant Breeding. This journal is edited by Dr. B. P. Pal, Imperial Agricultural Research Institute, New Delhi, on behalf of the executive council of the Society. This welcome addition to genetical publications provides a valuable outlet and source of reference for the everincreasing work of the research institutes of India. The volume for 1941 consists of one part, but in the succeeding years it is intended to publish twice a year.

In the first volume there are articles on hybrid vigour in rice by $K$. Ramiah and $K$. Ramasamy, chlorophyll deficiencies in rice by B. S. Kadam, colchicine induction of polyploids in Capsicum annuum by B. P. Pal, S. Ramanujam and A. S. Joshi, cytology of sterile Sesamum orientale by L. S. S. Kumar and A. Abraham and vernalization of Indian crop plants by B. P. Pal and G. Suryanarayana Murty. The Agricultural Commissioner with the Government of India, Dr. W. Burns, in the first paper of the publication, points out the great opportunities for plant geneties and plant breeding in India and welcomes the advent of the Society and Journal. 